\title{
Laboratory Full-Scale Comparative Tests of Rigid and Flexible Foundations of Buried Steel Structures
}

\author{
Adam Wysokowski ${ }^{1}$ - Michał Mońka
}

Received: 29 January 2019 / Accepted: 20 February 2020 / Published online: 27 February 2020

(c) The Author(s) 2020

\begin{abstract}
The technical issues described in the article concern the aspects of the implementation of foundations for buried flexible steel structures. The modernity of these objects has surpassed the solutions applied for their foundations. The foundations of these structures are most frequently made as traditional "rigid" structures (which is related to their massiveness-most commonly made of reinforced concrete). The article discusses laboratory comparison tests of two types of foundations of a buried flexible structure - a rigid (concrete) and flexible foundation (made as corrugated steel plates) and their results.
\end{abstract}

Keywords Buried flexible steel structures $\cdot$ Flexible steel foundations $\cdot$ Full-scale laboratory tests $\cdot$ Optimization

\section{Introduction}

Considering the rapid expansion of transport infrastructure, modern solutions such as flexible structures are becoming increasingly popular in civil engineering. This is due to the indisputable advantages of these structures (Janusz and Madaj 2007; Wysokowski 2017). The development of these technologies, however, is often ahead of the legislation and engineering practice. Flexible shell structures take advantage of the coaction of a thin shell with the soil backfill, thus both the fill and shell are the structural elements here, and not, as is the case with rigid structures, merely a backfill (Machelski 2008; Abuhajar et al. 2015; Rowińska et al. 2004). The technical issues described in this article refer to the aspects of making foundations for such "light" buried steel structures. The innovation of these structures has surpassed the methods of making foundations, which are most often rigid structures (and, due to their weight, are frequently made of reinforced concrete). The optimisation refers not only to the development of innovative solutions

Adam Wysokowski

awysokowski@infra-kom.eu

1 Road and Bridges Department, Faculty of Civil Engineering, Architecture and Environmental Engineering, University of Zielona Góra, Prof. Z Szafrana Street No. 1, Building A-8, 65-417 Zielona Góra, Poland

2 Viacon Poland Sp. z o.o., Rydzyna, Poland and the use of state-of-the-art construction materials, but also involves economic and environmental aspects.

As required by most applicable standards, foundations need to be designed in compliance with the standard for bridge structures. In this case, a foundation should be made as a massive continuous reinforced concrete structure, i.e. a foundation footing. The applicable standards, however, do not address the peculiarities of buried shell structures, which require such foundations to be redesigned in terms of load-bearing capacity and, consequently, dimensions. This directly increases the duration and costs of the execution of this type of structures.

For this reason, among others, such structures have been more and more frequently constructed with the use of flexible foundations in recent years, mostly in the form of corrugated steel plates of various dimensions, thickness and corrugation density (Pettersson and Sundquist 2014). Such solutions had been applied in a number of transport infrastructure facilities, and so far there have been no objections related to their operation (i.e. load-bearing capacity, subsidence, etc.). Also the technology of founding buried shell structures on flexible foundations is popular for difficult soil conditions.

Figure 1 shows an example of such structures.

This method of making foundations for flexible shell structures appears to be more advantageous due to the uniformity of the overall structure. In this case, both the structure and its foundation are flexible. In the case of flexible foundations with appropriate characteristics of subsoil, it 
Fig. 1 Examples of founding a structure with a corrugated sheet foundation: a typical solution of steel flexible foundation, b foundation of box-culvert structure in case of difficult soil and water conditions
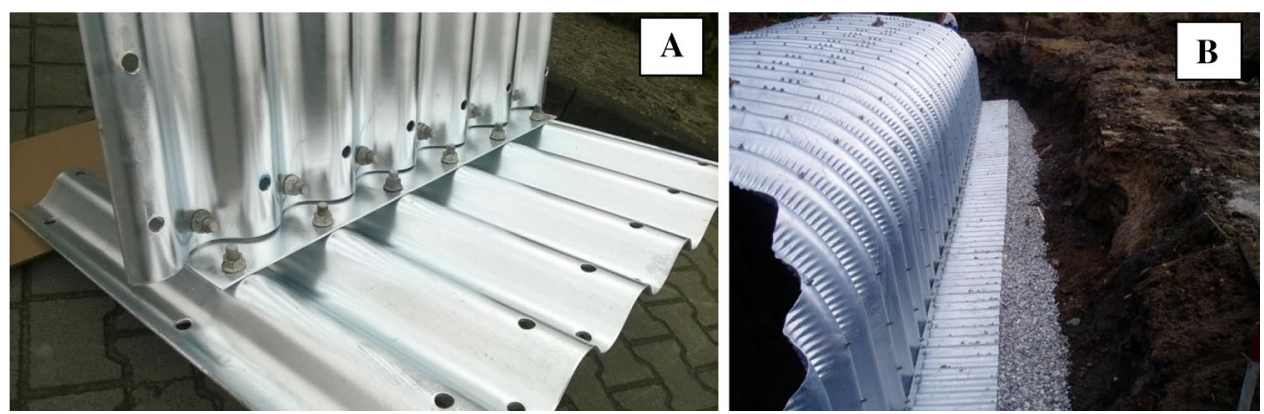

is possible to ignore the soil freezing zone, which is a key factor when dealing with rigid foundations. The conducted FEM analyses indicate a high load-bearing capacity tolerance of flexible foundations made of corrugated plates for variable characteristics of subsoil. Therefore, this article aims to present the options of the widespread application of flexible foundations in terms of future development trends. The comparison of these two issues-the flexibility of a supporting structure and the rigidity of its foundation-was the basis and incentive for carrying out the relevant research and analyses. Thus, the above issues were thoroughly investigated, followed by full-scale laboratory tests the results of which are presented in this article. The primary objective of this study was to demonstrate the differences in the behaviour of buried shell structures on two types of foundations. The aim of laboratory tests on a natural scale was also to create a knowledge base on the behaviour of buried structures on two types of foundations. This database, in its assumption, allows the verification of calculations performed by a numerical method such as FEM.

\section{Description of Tests}

The authors have actively participated in implementing these types of structures in Poland (Wysokowski and Janusz 2007; Wysokowski and Vaslestad 2002). A number of studies on such structures, both laboratory-on a natural scale, as well as in-field were carried out (under static and dynamic loads, as well as in terms of fatigue and durability). The foundation conditions of these structures were also analysed in these studies.

The analysed structure was founded on two kinds of foundations, i.e. rigid (reinforced concrete foundations) and flexible type (corrugated steel plates arranged horizontally).

The structures comprised two arch-shaped culverts made of corrugated steel plates (HelCor type) with identical dimensions. Each analysed structure had a length of to $4.00 \mathrm{~m}$, a clear width of $2.50 \mathrm{~m}$, and a clear height of $1.25 \mathrm{~m}$ (Wysokowski and Górna 2007). Basic parameters of the structures are summarized in Table 1.
Table 1 Parameters of corrugated steel structures

\begin{tabular}{llr}
\hline Parameter & Unit & Value \\
\hline Sheet thickness & $(\mathrm{mm})$ & 2.0 \\
Weight & $(\mathrm{kg} / \mathrm{m})$ & 47.8 \\
Tensile strength & $(\mathrm{MPa})$ & 270.0 \\
Yield point & $\mathrm{MPa}$ & 250.0 \\
\hline
\end{tabular}

Table 2 Parameters of soil backfill used in laboratory tests

\begin{tabular}{llc}
\hline Parameter & Unit & Value \\
\hline Sand indicator & $\%$ & 92.5 \\
Optimal moisture & $\%$ & 9.5 \\
Compaction by Proctor & $\mathrm{g} / \mathrm{cm}^{3}$ & 1.990 \\
Bulk density & $\mathrm{g} / \mathrm{cm}^{3}$ & 1.74 \\
Bearing capacity CBR (5.0) & $\%$ & 17.0 \\
$\begin{array}{l}\text { Aggregate abrasion by the Los Angeles } \\
\text { method }\end{array}$ & $\%$ & 26.0 \\
\hline
\end{tabular}

It should be noted the development of the research models was accompanied by comprehensive studies of the soilboth the subsoil and the backfill.

In the first stage of soil testing, the test consisted in checking the suitability of the soil for backfilling from various mines. On this basis, the selection of an appropriate material was made. Then, detailed research was conducted on all relevant soil parameters, including:

(a) the density indicator,

(b) the stiffness module,

(c) the angle of internal friction,

(d) the graining curve,

(e) soil moisture.

The basic parameters of soil backfill are summarized in Table 2.

At the level of individual layers ( $0.20 \mathrm{~m}$ thick), compaction tests were carried out under the foundations. After obtaining the appropriate parameters, a decision was made to lay down subsequent layers. After installing pressure 


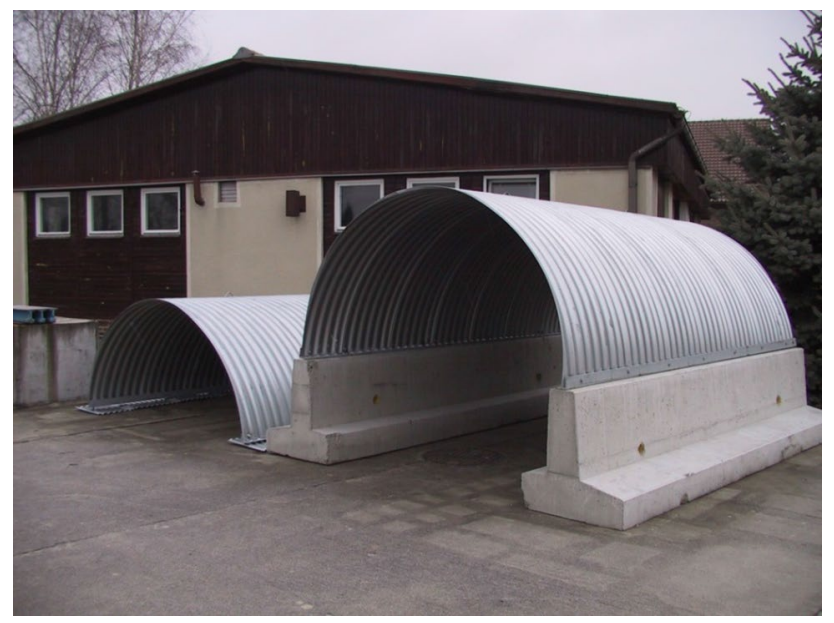

Fig. 2 General view of structures for testing

gauges and assembling the steel structure with the foundations, successive layers of backfill were made within the coating (thickness $0.25-0.40 \mathrm{~m}$ ).

A general view of both structures before testing is shown in Fig. 2.

An analysis of compaction was carried out on a regular basis both when preparing the foundation of the structure, as well as upon adding the respective layers of soil backfill.
The required degree of compaction was $98 \%$ Standard Proctor density.

The over layer above the shell structures was $0.60 \mathrm{~m}$, which is the minimum for this type of culvert for withstanding moving loads in compliance with top load class. The adopted minimum surcharge allowed for the comparative analysis of the behaviour of the two structures to be carried out in laboratory conditions.

The tests were carried out with the soil load (during backfilling of the steel structure) and then under the road load according to the Class A standard (500 kN of load).

In order to simulate the standard load, the load transfer system was applied to the tested model (Fig. 4a).

Figures 3 and 4 shows the individualstages of making models of structures for testing and further research.

The width of the reinforced concrete foundations was $0.75 \mathrm{~m}$ and the thin-wall steel foundations was $0.50 \mathrm{~m}$. The geometrical parameters of the test models are shown in Fig. 5.

Figure 6 presents the static schemes of both models, and the theoretical model of shell deformation depending on the type of foundation. Figure 7 shows the details of connection between the arch-shaped culvert and its foundation.

The following sensors were used for the tests:

- Soil pressure meters.

- Strain gauges (stresses).
Fig. 3 Early stages of making models of structures for research: a view of the structure for testing with flexible foundations, $\mathbf{b}$ view of one of the presiometers during backfilling of flexible steel structure


Fig. 4 View of the final stage of building models for research: a general view of a steel structure simulating the load in accordance with the normative standard, $\mathbf{b}$ view of a ready-made research model in natural scale
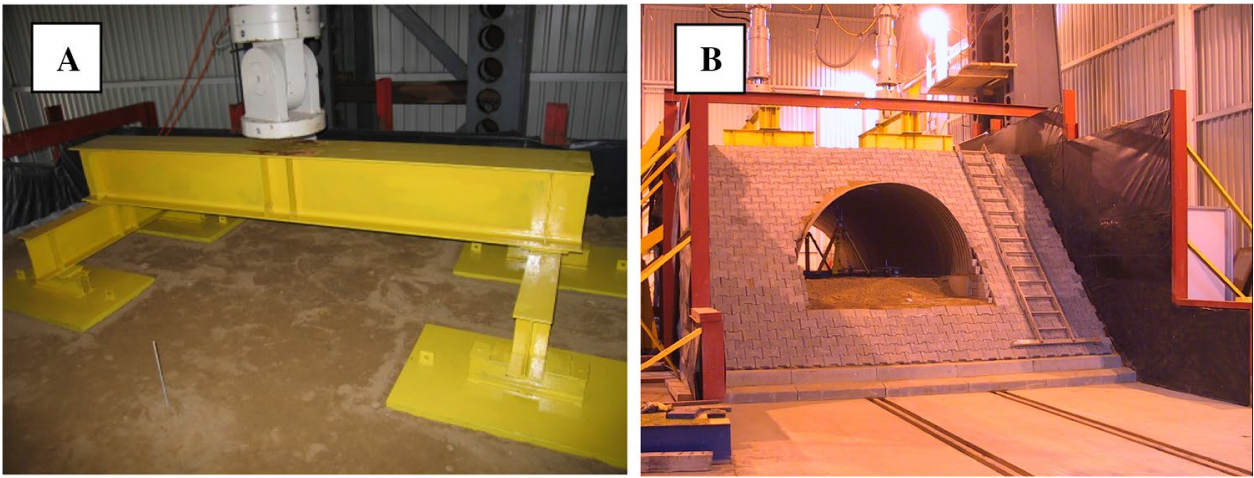
Fig. 5 Geometrical parameters of the test models: a crosssection of structure with rigid foundation, $\mathbf{b}$ Cross-section of structure with flexible foundation, $\mathbf{c}$ top view of testing models
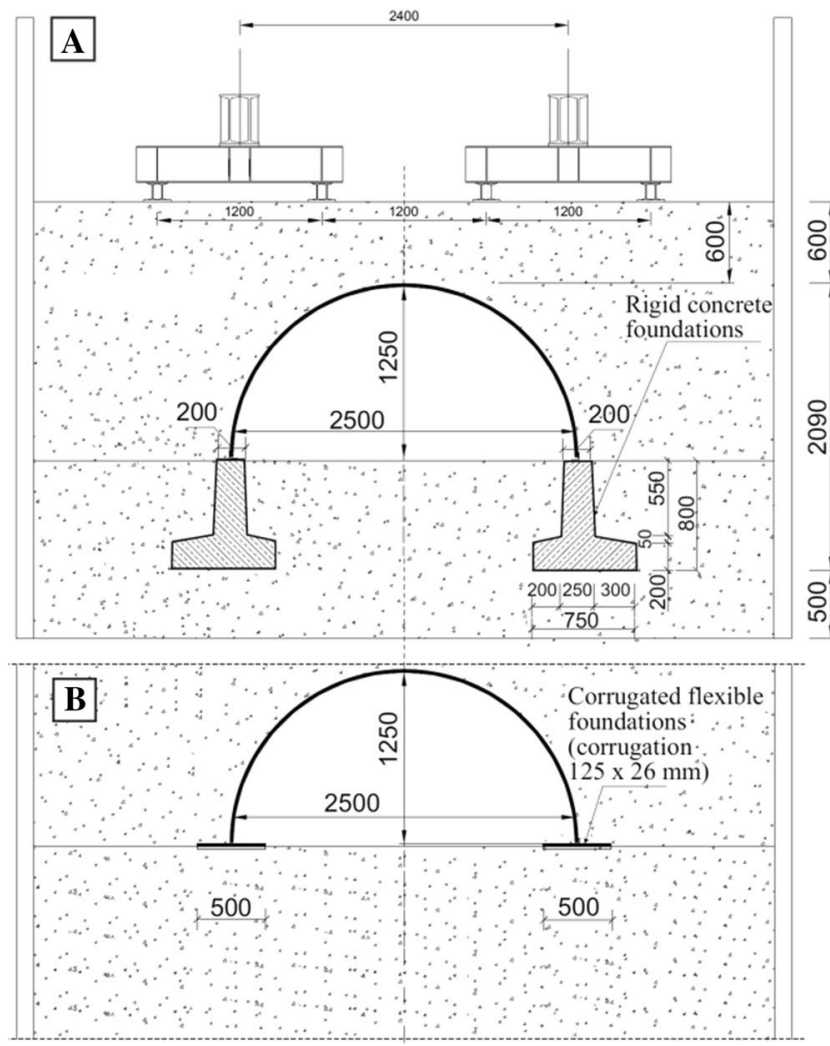

- Inductive sensors (deflection).

Figure 8 presents the measurement scheme for both analysed test models.

The pressure meters used to analyse soil stress were located in the foundation area to obtain the maximum possible reliable information on the actual behaviour of the structures.

\subsection{Design Standards}

According to the Polish Standards in the case of buried structures most important parameter is the allowable deflection, which is equal to $3 \%$. When designing this type of structure, it is necessary to estimate the value of the maximum deflection during use of the object and compare it with the permissible value. Deflection of the structure results from the displacement and the span ratio.

During the implementation of culverts made of corrugated steel plates, compliance with the permissible values of wall stresses must be checked. The allowable stress value in this case is equal to the tensile strength of the steel from which the buried structure was made.

\section{Test Results}

In order to reliably determine the results of the structural foundation type, the following tests were carried out:

- stresses under the foundation in soil during the backfilling of the structure,

- stresses under the foundation in soil with a load (3 types of standard load L1, L2, L3),

- displacements of the crown of the structure during the backfilling,

- displacements of the crown of the structure with the loads.

Table 3 presents a summary of the stress values under both foundations during the backfilling of the test models (level "zero" was assumed at the top level for both foundations).

The graph in Fig. 9 presents the values of the vertical displacement of the crown of the structure with a rigid foundation during backfilling. 
Fig. 6 Static schemes of both models, and the theoretical model of shell deformation on two types of fundation
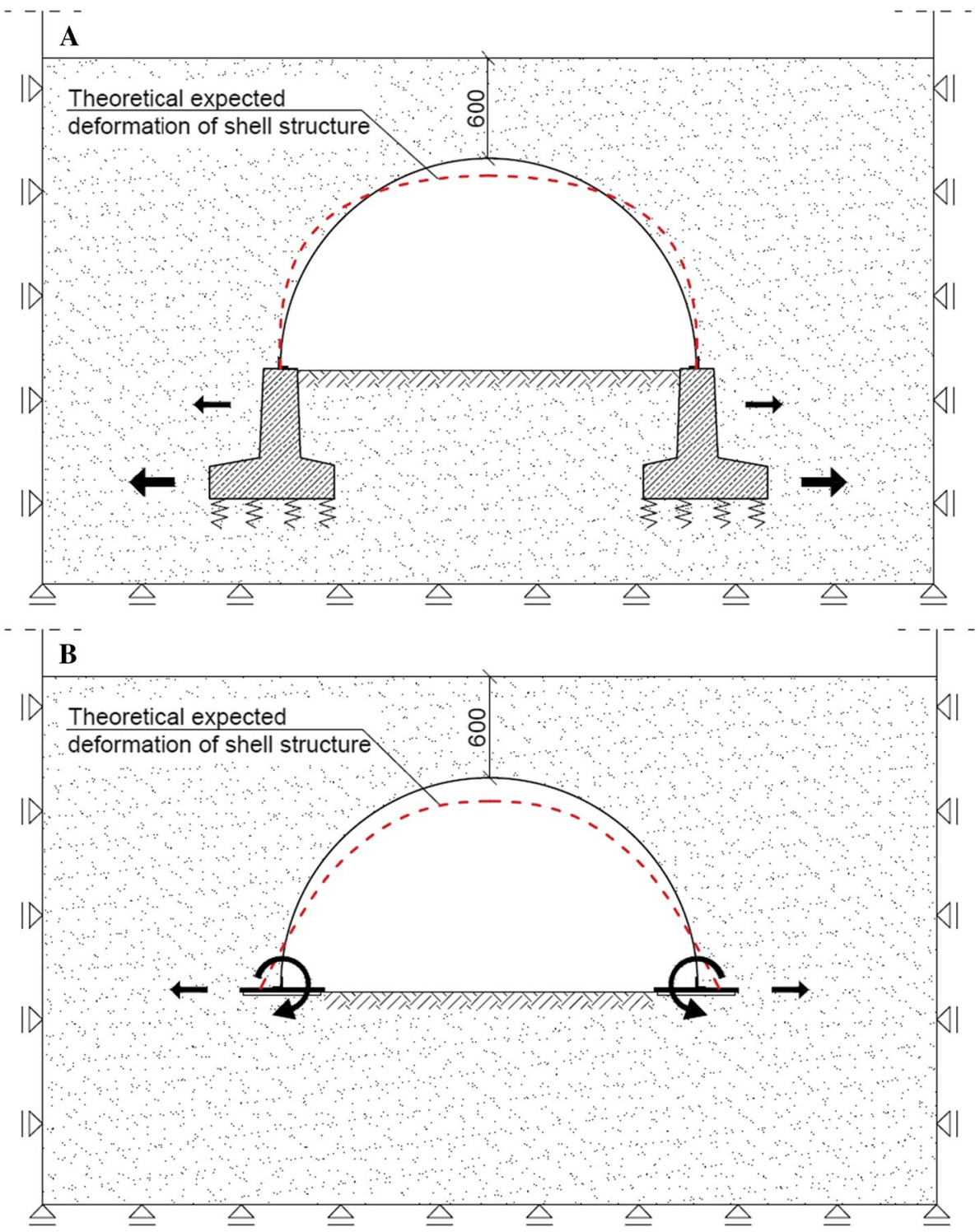

The graph in Fig. 10 presents the values of vertical displacement of the crown of the structure with a flexible foundation during backfilling.

Table 4 presents a summary of the recorded values of the vertical displacement of the crown structure due to the application of three cycles of standard loads.

Table 5 compares the maximum displacement and stress values measured for the research models with the permissible standard values.

Further static loading cycles (L1, L2, L3) were applied after full "relaxation" of the structure.

\section{Analysis of Results}

The study revealed the conformity of the values of the vertical displacement (under successive standard loads) of the developed structures based on a reinforced concrete rigid foundation and a flexible foundation made of corrugated steel plates. It should be noted at this point that the measured values of the vertical displacement of the crown of the steel shell are minor for both foundation types.

The results show that the backfilling of the structure situated on a flexible foundation for the purposes of the study is correct. This holds true for the values of stress under the foundation, as well as for the horizontal displacement and vertical displacement of the crown of the steel structure, i.e. the increase of its elevation, which is a typical phenomenon in buried flexible steel structures. 


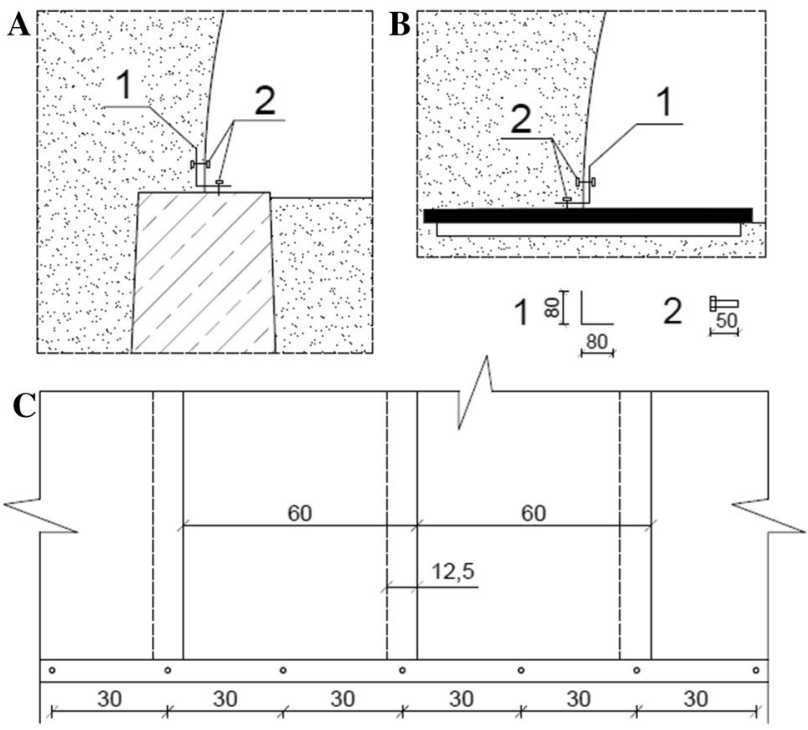

Fig. 7 Details of connection between the arch-shaped culvert and its foundation
The diagram in Fig. 11 presents the comparison of values for the vertical displacement of the crown of the structures during loading (L1-L3).

A similar conformity was also observed for other analysed parameters, such as horizontal displacement recorded for both foundation types.

The graph in Fig. 12 presents a comparative analysis of the stress values under a reinforced concrete foundation and under a steel sheet foundation recorded during the backfilling of both structures.

Figure 13 presents a graph with a comparison of the stress values under a reinforced concrete foundation and a steel sheet foundation recorded during the successive application of respective standard loads (L1-L3).

The analysis of the results showed that the stress values in the soil under the steel foundation (both during the backfilling of the shell and under successive standard loads are lower (even at a level of $67 \%$ at L3 load) than those recorded under the reinforced concrete foundation.
Fig. 8 Measurement scheme of testing models

Table 3 Values of stress under a foundation during backfilling
FLEXIBLE STEEL FOUNDATION

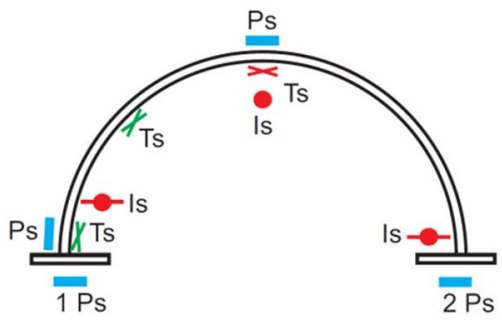

Description:

- Ps, Pc - Pressure meters

$>$ Ts, Tc - Strain gauges

- Is, Ic - Inductive sensors
RIGID CONCRETE FOUNDATION

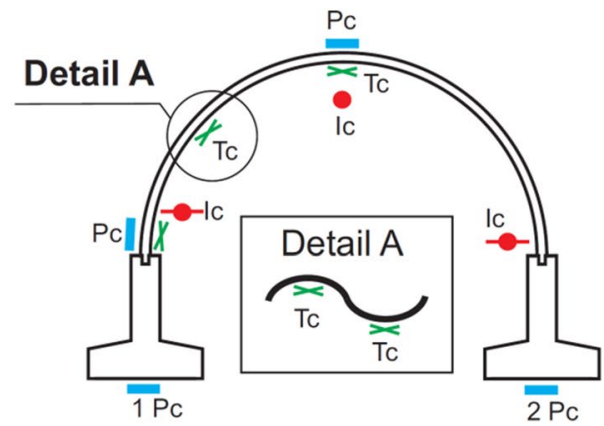

\begin{tabular}{|c|c|c|c|c|c|c|c|}
\hline \multicolumn{2}{|c|}{ Soil backfill } & \multicolumn{3}{|c|}{ Structure on a steel foundation } & \multicolumn{3}{|c|}{$\begin{array}{l}\text { Structure on a reinforced concrete } \\
\text { foundation }\end{array}$} \\
\hline $\begin{array}{l}\text { Layer } \\
\text { number } \\
(-)\end{array}$ & $\begin{array}{l}\text { Total backfill } \\
\text { height }(\mathrm{m})\end{array}$ & $1 \mathrm{Ps}(\mathrm{kPa})$ & 4Ps $(\mathrm{kPa})$ & $2 \mathrm{Ps}(\mathrm{kPa})$ & $1 \mathrm{Pc}(\mathrm{kPa})$ & $3 \mathrm{Pc}(\mathrm{kPa})$ & $2 \mathrm{Pc}(\mathrm{kPa})$ \\
\hline \multicolumn{8}{|c|}{ Stress in soil under the foundation due to backfilling } \\
\hline 1 & 0.35 & 0.0 & 0.0 & 0.1 & 0.7 & 0.4 & 0.8 \\
\hline 2 & 0.75 & 0.0 & 2.2 & 2.1 & 2.5 & 1.2 & 3.7 \\
\hline 3 & 0.95 & 1.3 & 5.2 & 3.7 & 4.4 & 2.1 & 5.8 \\
\hline 4 & 1.15 & 1.5 & 8.3 & 5.5 & 4.9 & 3.0 & 8.6 \\
\hline 5 & 1.35 & 0.0 & 7.1 & 4.3 & 5.7 & 3.4 & 12.6 \\
\hline 6 & 1.60 & 4.4 & 18.6 & 17.4 & 9.9 & 6.3 & 21.9 \\
\hline 7 & 1.85 & 0.0 & 18.6 & 15.3 & 9.2 & 6.4 & 21.8 \\
\hline
\end{tabular}

$1 \mathrm{Ps}, 2 \mathrm{Ps}$ and $1 \mathrm{Pc}, 2 \mathrm{Pc}$ pressure meters measure the stress directly under the foundation 
Fig. 9 Vertical displacement of the crown of the structure with a concrete foundation during backfilling

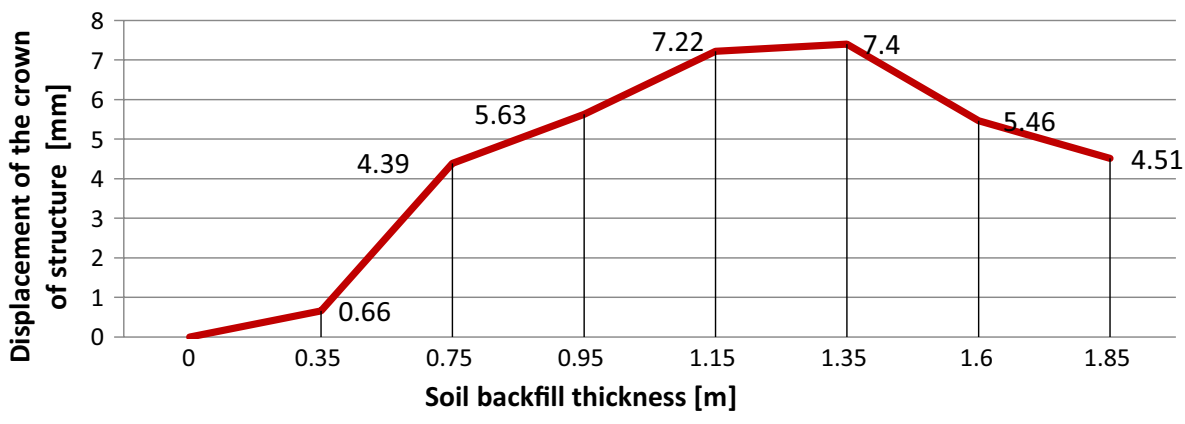

Fig. 10 Vertical displacement of the crown of the structure with a corrugated steel foundation during backfilling

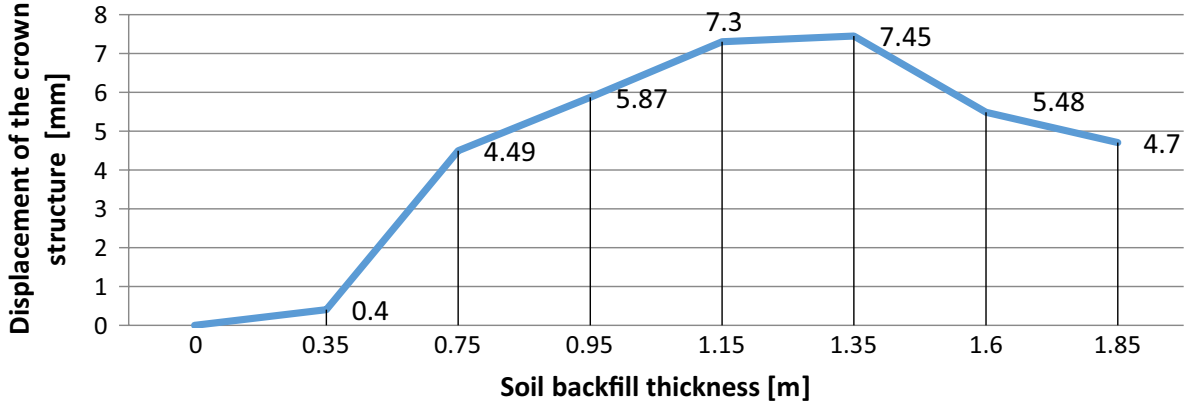

Table 4 Vertical displacement of the structure crown for the three cycles of applying standard loads

\begin{tabular}{lcl}
\hline Type of applied load & $\begin{array}{l}\text { Structure on a steel } \\
\text { foundation }(\mathrm{mm})\end{array}$ & $\begin{array}{l}\text { Structure on a } \\
\text { reinforced concrete } \\
\text { foundation }(\mathrm{mm})\end{array}$ \\
\hline Vertical displacement of the crown structure & under load \\
L1 & -4.27 & -4.12 \\
L2 & -4.81 & -4.69 \\
L3 & -5.16 & -5.00 \\
\hline
\end{tabular}

\section{Conclusions}

Due to the increasing popularity of buried shell structures in civil engineering, an effort should be made to gain the best insight possible into the behaviour and characteristics of such structures (Chen et al. 2016; Sanaeiha et al. 2017; El-Sawy 2003).
The research carried out showed that the behaviour of the structure based on the flexible foundation in terms of displacement fully coincides with the structure founded on rigid foundations.

The analysis of the test results showed that the stresses in the ground under the flexible steel foundations (both during backfilling and under subsequent standard loads) are smaller than those registered under the reinforced concrete foundations. It should be noted that, in both cases, the recorded values of these stresses are still relatively small.

This fact is directly related to the "flow" of forces in the soil and the buried soil-shell structures, where most of the loads are taken over by the backfill, thanks to the phenomenon of blanking. The tests also confirmed the assumed theoretical deformations of thin-walled steel structure for both-rigid and flexible foundations.

Steel footing with low corrugation on a very compacted soil may result in a triangular pressure distribution with a
Table 5 Comparison of maximum displacement and stress values with the permissible standard values

\begin{tabular}{llll}
\hline Research model & Parameter & Value & $\begin{array}{l}\text { Permissible standard value } \\
\text { according to Polish standards } \\
(\%)\end{array}$ \\
\hline $\begin{array}{c}\text { Structure on cor- } \\
\text { rugated flexible } \\
\text { foundations }\end{array}$ & Deflection & $(5.16: 2500.0) \cdot 100 \%=0.21 \%$ & 3 \\
$\begin{array}{c}\text { Structure on rigid } \\
\text { concrete founda- } \\
\text { tions }\end{array}$ & Deflection & $(5.00: 2500.0) \cdot 100 \%=0.20 \%$ & 3 \\
\hline
\end{tabular}


Fig. 11 Vertical displacement of the crown of the analysed structures under load (L1-L3)
Fig. 12 Comparison of the stress values under a reinforced concrete foundation and a steel sheet foundation recorded during the backfilling of the structures
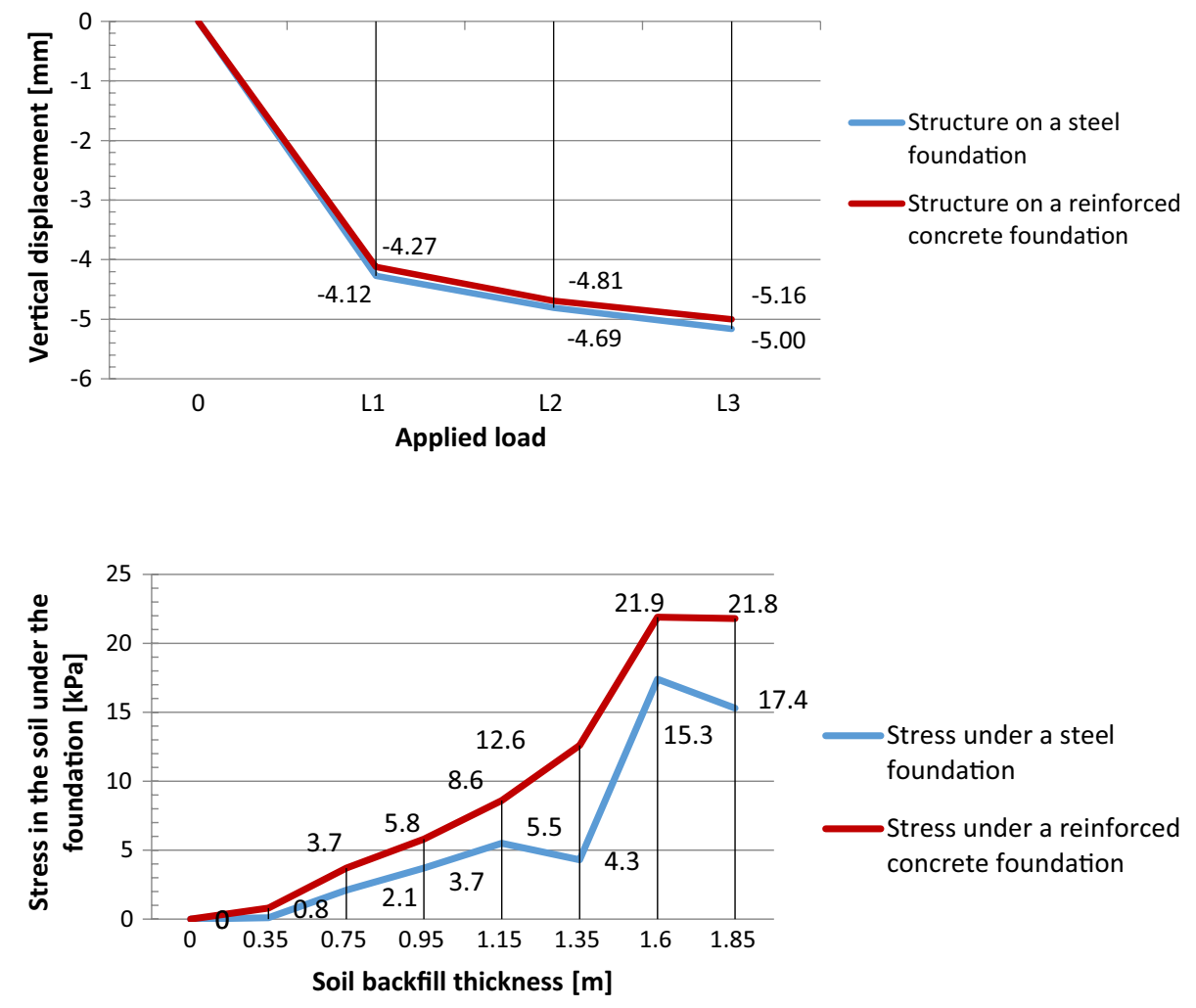

Fig. 13 Comparison of the stress values under a reinforced concrete foundation and a steel flexible foundation recorded during the successive application of standard loads

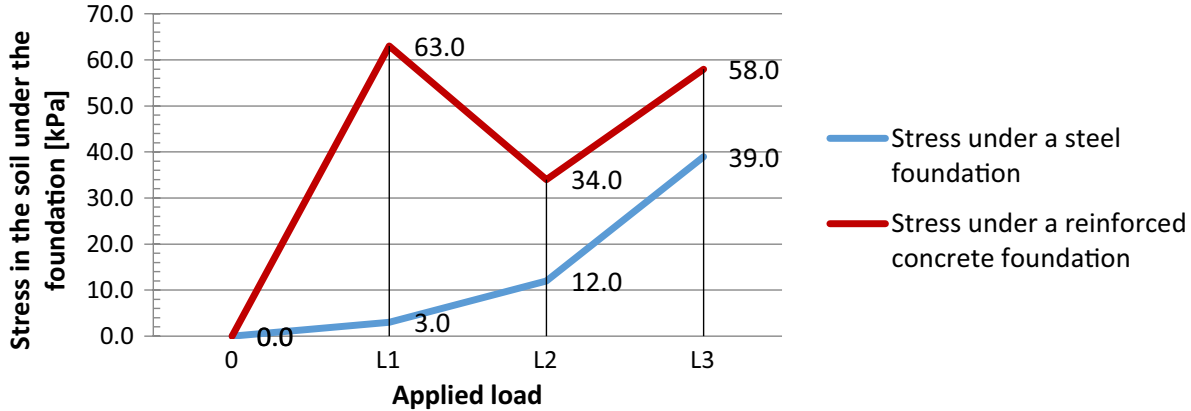

maximum bearing pressure in the axis of steel structure. It should be noticed that metal footings can deflect somewhat perpendicular to the axis of the structure, thus they should be carefully built on soil. In the case of the test model, the same corrugation as for culvert construction was used for flexible foundations to avoid differences in stiffness.

A very important and interesting advantage of such foundation structures may be the possibility of their adapting to the foundation conditions, especially for weak, temporary or variable soil conditions; this, however, requires accounting for the work of the folded shell and its connection with the flexible foundation.

In the case of concrete foundation it is recommended that additional protective measures for ground water level and sulfate concentrations is needed to avoid corrosion of footing structure.
The authors suggest that deeper analyses of such structures be carried out as a follow-up to the presented research. This will inevitably contribute to further optimisation of buried shell structures and, consequently, reduce the costs of infrastructure projects which take advantage of such solutions. In terms of practical applicability, the research carried out so far supports the claim that the trend recently observed in engineering practice, i.e. the use of flexible foundations made of corrugated steel plates for buried flexible structures has no detrimental impact whatsoever on their behaviour under exploitation load.

Measurement data obtained during the laboratory tests in natural scale, in addition to the basis for scientific studies, give the possibility of more accurate calibration and verification of calculations performed by analytical and numerical method such as FEM. When using FEM method, two 
parameters are most important: the choice of the soil model and the modeling of the concrete and steel elements. However in order to represent relevant features of the expected stress strain response in the ground, should be used for a realistic calculation of the load-settlement behaviour. The authors also point to the need for further intensified analytical and numerical studies on this foundation method.

Open Access This article is licensed under a Creative Commons Attribution 4.0 International License, which permits use, sharing, adaptation, distribution and reproduction in any medium or format, as long as you give appropriate credit to the original author(s) and the source, provide a link to the Creative Commons licence, and indicate if changes were made. The images or other third party material in this article are included in the article's Creative Commons licence, unless indicated otherwise in a credit line to the material. If material is not included in the article's Creative Commons licence and your intended use is not permitted by statutory regulation or exceeds the permitted use, you will need to obtain permission directly from the copyright holder. To view a copy of this licence, visit http://creativecommons.org/licenses/by/4.0/.

\section{References}

Abuhajar, O., El Naggar, H., \& Tim, N. T. (2015). Static soil culvert interaction the effect of box culvert geometric configurations and soil properties. Computers and Geotechnics, 69, 219-235.

Chen, B., Song, D., Mao, X., Chen, E. J., \& Zhang, J. (2016). Model test and numerical simulation on rigid load shedding culvert backfilled with sand. Computers and Geotechnics, 79, 31-40.

El-Sawy, K. M. (2003). Three-dimensional modeling of soil-steel culverts under the effect of truckloads. Thin-Walled Structures, 41(8), 747-768.
Janusz, L., \& Madaj, A. (2019). Buried flexible steel structures. Designing and execution. Warsaw: Transport and Communication Publishers.

Machelski, C. Z. (2008). Calculations for buried shell bridges., Wrocław publishing series on bridge engineering Wrocław: Lower Silesia Educational Publishing.

Pettersson, L., \& Sundquist, H. (2014). Design of soil steel composite bridges. TRITA-BKN. Report 112, 5th Edition. ISSN 1103-4289.

Rowińska, W., Wysokowski, A., \& Pryga, A. (2004). Design and technology recommendations for buried flexible steel engineering structures. Żmigród: General Directorate of National Roads and Motorways, Road and Bridge Research Institute.

Sanaeiha, A., Rahimian, M., \& Sadegh, M. M. (2017). Field test of a large-span soil-steel bridge stiffened by concrete rings during backfilling. Journal of Bridge Engineering, 22(10), 06017002.

Wysokowski, A. (2017). Durability of flexible steel corrugated shell structures-theory and practice. Archives of Institute of Civil Engineering (ACEI), 23, 347-361. https://doi.org/10.21008 /j.1897-4007.2017.23.32.

Wysokowski, A., \& Górna, J. (2007). Study of a steel flexible structure on a reinforced concrete foundation and a corrugated steel foundation. Part 1, Part 2, Part 3. Report No. IBDIM-TW 66907a/W1569 (in polish) Żmigród, Poland.

Wysokowski, A., \& Janusz, L. (2007). General conclusions based on the testing of various types of corrugated flexible structures in laboratory in natural scale. Archives of Institute of Civil Engineering, 1, 273-286.

Wysokowski, A., \& Vaslestad, J. (2002). Full scale fatigue testing of large-diameter multi-plate corrugated steel culverts. Archives of Civil Engineering, 48(1), 31-57.

Publisher's Note Springer Nature remains neutral with regard to jurisdictional claims in published maps and institutional affiliations. 